\title{
APLIKASI NEUROMUSCULAR TAPING PADA KONDISI CARPAL TUNNEL SYNDROM UNTUK MENGURANGI NYERI
}

\author{
Ayu Permata ${ }^{\text {1) }}$ Ismaningsih ${ }^{2)}$ \\ 1,2,3) Program Studi D-III Fisioterapi \\ Fakultas Kedokteran dan Ilmu Kesehatan \\ Universitas Abdurrab \\ Jl. Riau Ujung no. 73 Pekanbaru \\ email : ${ }^{1)}$ ayu.permata@univrab.ac.id
}

\begin{abstract}
Background: Carpal tunnel syndrome (CTS) is a collection of symptoms and signs of disease caused by squeezing of the median nerve in the carpal tunnel in the wrist. This CTS condition is one of the most common types of neuropathy. This syndrome arises with symptoms of pain, numbness, and weakness in the hands due to compression of the median nerve. Carpal tunnel syndrome is a syndrome associated with repetitive motion and a fixed position for a long duration so that it affects the blood supply to the hands and causes pain. Objective: This research is aimed at sufferers of Carpal Tunnel Syndrome condition to reduce pain. Physiotherapy interventions given in CTS conditions, namely pain reduction that can be done with various actions including by providing Neuromuscular Taping technique. Research Method: Case study with pre and post test research design that compares the level of pain values before and after which is measured by measuring instruments Visual Analogue Scale (VAS) for the administration of Neuromuscular Taping intervention in the condition of carpal tunnel syndrome for 3 weeks. Results: Analysis of the different values of pain tests with VAS in the sample group with a significance value of 0.006 which shows $<0.05$ which means there is an influence of giving Neruromusculer taping to changes in the VAS pain level in patients with Carpal Tunnel Syndrome.
\end{abstract}

Keywords : Carpal Tunnel Syndrome, Physiotherapy, Neuromuscular Taping, Visual Analogue Scale, Case Study

\begin{abstract}
Abstrak
Latar Belakang: Carpal tunnel syndrome (CTS) merupakan kumpulan gejala dan tanda penyakit yang disebabkan oleh terjepitnya saraf medianus di terowongan karpal pada pergelangan tangan. Kondisi CTS ini merupakan salah satu jenis neuropati yang paling sering terjadi. Sindrom ini timbul dengan gejala nyeri, baal, dan kelemahan pada tangan akibat penekanan nervus medianus. Carpal tunnel syndrome merupakan suatu syndrome yang berhubungan dengan gerakan yang berulang (repetitive motion) dan posisi yang menetap pada durasi yang lama sehingga memperngaruhi suplai darah ke tangan dan menimbulkan rasa nyeri. Tujuan: Penelitian ini ditujukan kepada penderita kondisi Carpal Tunnel Syndrom untuk mengurangi nyeri. Intervensi fisioterapi yang diberikan pada kondisi CTS yaitu penurunan nyeri yang dapat dilakukan dengan berbagai tindakan diantaranya dengan pemberian teknik Neuromuskuler Taping Metode Penelitian: Case study dengan desain penelitian pre and post test yaitu membandingkan antara tingkat nilai nyeri sebelum dan sesudah yang diukur dengan alat ukur Visual Analogue Scale (VAS) terhadap pemberian intervensi Neuromuskuler Taping pada kondisi carpal tunnel syndrome selama 3 mingggu. Hasil: Analisa uji beda nilai nyeri dengan VAS pada kelompok sampel dengan nilai signifikasi yaitu 0,006 yang menunjukkan < 0.05yang bermakna ada pengaruh pemberian Neruromusculer taping terhadap perubahan tingkat nyeri VAS penderita Carpal Tunnel Syndrom.
\end{abstract}

Kata kunci : Carpal Tunnel Syndrom, Fisioterapi, Neuromuskuler Taping, Visual Analogue Scale, Case Study 


\section{Pendahuluan}

Carpal tunnel syndrome (CTS) merupakan kumpulan gejala dan tanda penyakit yang disebabkan oleh terjepitnya saraf medianus di terowongan karpal pada pergelangan tangan. Kondisi CTS ini merupakan salah satu jenis neuropati yang paling sering terjadi. Sindrom ini timbul dengan gejala nyeri, baal, dan kelemahan pada tangan akibat penekanan nervus medianus. Carpal tunnel syndrome merupakan suatu syndrome yang berhubungan dengan gerakan yang berulang (repetitive motion) dan posisi yang menetap pada durasi yang lama sehingga memperngaruhi suplai darah ke tangan dan menimbulkan rasa nyeri.

Penelitian yang dilakukan oleh Armsrong (2008) di kawasan indsutri kerja ada empat sebagai faktor kontrol dari perkembangan Carpal tunnel syndrome yaitu jenis kelamin, usia, index massa tubuh (IMT) dan penyakit penyerta. Carpan tunnel syndrome merupakan hasil dari kombinasi kondisi kesehatan dan aktivitas fisik yang berulang yang dapat meningkatkan tekanan pada nervus medianus saat melewati terowongan karpal.

Carpal Tunnel Syndrome adalah neuropati akibat terjepitnya saraf yang terjadi ketika saraf medianus pada pergelangan tangan tergencet oleh pembungkus tendon fleksor yang mengalami penebalan, terkaitnya tulang, odema atau massa jaringan lunak. Menurut Long, carpal tunnel syndrome disebabkan oleh tekanan pada nervus median dari pergelangan tangan. Kondisi ini biasa terjadi pada usia pertengahan, pada wanita gemuk kemungkinan terjadi akibat dari trauma atau pembengkakan yang disebabkan oleh proses rheumatoid arthritis [1].

Carpal tunnel syndrome adalah salah satu dari 3 jenis penyakit yang tersering di dalam golongan Cummulative Trauma Disorders (CTD) dengan prevalensi sebesar 40\%, sedangkan CTD merupakan penyebab lebih dari $50 \%$ penyakit akibat kerja pada anggota gerak atas. Sebagai salah satu dari 3 jenis penyakit tersering di dalam golongan CTD pada ekstremitas atas, prevalensi STK besarnya $40 \%$, tendosinovitis yang terdiri dari trigger finger sebesar $32 \%$ dan De Quervan's syndrome $12 \%$, sedangkan epicondilitis sebesar $20 \%$ [2].

Pada tahap awal gejala yang paling sering muncul di malam hari ketika tangan dalam kondisi istirahat. Dengan perkembangan penyakit lebih lanjut, gejala-gejala juga akan muncul di siang hari, terutama dengan kegiatan yang menggunakan gerakan pergelangan tangan yang berulang, seperti ketika menggambar, menjepit, mengetik, mencuci atau gerakan memeras. Pada penyakit yang lebih lanjut, gejalanya nyeri terjadi secara menetap.

Rasa nyeri ini terjadi akibat penyempitan pada terowongan karpal, baik akibat edema fasia pada terowongan tersebut maupun akibat kelainan pada tulang-tulang kecil sehingga terjadi penekanan terhadap nervus medianus dipergelangan tangan. Nyeri yang diakibatkan oleh kondisi carpal tunnel syndrome timbul ketika jaringan sedang rusak, dan menyebabkan individu bereaksi untuk menghilangkan rasa nyeri.

National Health Interview Study (NIHS) memperkirakan bahwa prevalensi CTS yang dilaporkan sendiri diantara populasi dewasa adalah sebesar $1,55 \%$ (2,6 juta). CTS lebih sering mengenai wanita daripada pria, dengan usia berkisar $25-64$ tahun. Prevalensi tertinggi pada wanita usia $>55$ tahun. Biasanya antara $40-60$ tahun. Prevalensi CTS dalam populasi umum telah diperkkirakan $5 \%$ untuk wanita dan $0,6 \%$ untuk laki-laki. CTS adalah jenis neuropati jebakan yang paling sering ditemui. Sindroma CTS ini uniletaral pada $42 \%$ kasus (29\% kanan, 13\% kiri) dab 58\% bilateral [3].

Menurut data RSUD Arifin Achmad Pekanbaru pada tahun 2012 ditemukan pada 15 kasus besar di instalasi rehabilitasi medik RSUD Arifin Achmad Pekanbaru pasien rawat jalan dengan kondisi Carpal tunnel syndrome berada pada urutan ke 10 dengan jumlah penderita 281 dengan jumlah keseluruhan pasien pada kasus besar di instalasi rehabilitasi medik RSUD Arifin Achmad pekanbaru 10.949. Resiko terjadinya carpal tunnel syndrome 10\% lebih banyak pada orang dewasa. Wanita beresiko tiga kali lipat lebih banyak dari pada pria dan terbanyak terjadi pada usia 40-50 tahun.

Salah satu pelayanan kesehatan untuk menangai permasalahan gerak dan fungsi dalam pemeliharaan dan peningkatan kualitas hidup manusia yaitu pelayanan fisioterapi. Pada kondisi nyeri yang diakibatkan oleh kondisi carpal tunnel syndrome yaitu dengan memberikan neuromuscular taping. Neuromusculer taping adalah salah satu metode terapi biomekanikal yang inovatif dengan stimulasi kompresi dan dekompresi untuk menghasilkan efek yang positif pada sistem saraf, vaskuler dan limfatik. Efek neuromuskuler taping pada level sensoris dapat menstimulasi kutaneus, otot, resepteor sendi dan mengontrol nyeri [4].

Neuromuscular Taping (NMT) dengan aplikator tape menciptakan kekuatan eksentrik yang diterapkan pada kulit dan berperan dalam mengatur sensorik dan system propioseptif. Neuromuscular Taping (NMT) memodifikasi input sensorik yaitu diintegrasikan oleh system saraf pusat dan digunakan untuk membantu proses eksekusi program motor yang dikenal dengan integrasi sensomotoris. NeuroMuscular Taping (NMT) memiliki fungsi menormalkan fungsi otot, 
meningkatkan aliran limfik dan pembuluh darah, mengurangi rasa sakit, menguatkan otot yang lemah, dan membantu postural dan rileksasi otot yang terlalu sering digunakan [5].

\section{Tinjauan Pustaka}

\subsection{Patofisiologi}

Carpal Tunnel Syndrome adalah gejala neuropati kompresi dari N. medianus di tingkat pergelangan tangan, ditandai dengan bukti peningkatan tekanan dalam terowongan karpal dan penurunan fungsi saraf di tingkat itu. Carpal Tunnel Syndromedapat disebabkan oleh berbagai penyakit, kondisi, dan peristiwa. Hal ini ditandai dengan adanya keluhan mati rasa, kesemutan, nyeri tangan dan lengan, dan disfungsi otot. Kelainan ini tidak dibatasi oleh usia, jenis kelamin, etnis, atau pekerjaan melainkan disebabkan karena penyakit sistemik, faktor mekanis dan penyakit lokal [6].

Carpal tunnel syndrome (CTS) adalah entrapment neuropathy (jebakan saraf) yang disebabkan oleh kompresi saraf medianus saat melewati terowongan karpal pada pergelangan tangan. Kondisi ini merupakan jebakan saraf yang paling umum, mencakup $90 \%$ dari semua neuropati. Gejala pertama dari carpal tunnel syndrom termasuk nyeri, mati rasa dan parestesia. Gejala-gejala ini umumnya muncul, dengan variabilitas tertentu, di ibu jari, telunjuk, jari tengah dan setengah radial (sisi ibu jari) dari jari manis. Rasa sakit juga bisa menjalar ke lengan yang terkena, kelemahan tangan, penurunan koordinasi motorik halus dan atrofi otot bagian tenar. Gejala sindroma ini biasanya dimulai dengan gejala sensorik yaitu nyeri, kesemutan (parestesia), rasa tebal (numbness) dan rasa seperti terkena aliran listrik (tingling) pada daerah yang dipersarafi oleh n.medianus.

Pada umumnya CTS terjadi secara kronis karena faktor mekanik dan faktor vaskuler. Faktoir mekanik terjadi akibat terjadinya gerakan berulang oleh pergelangan tangan dengan kontraksi yang kuat sehingga menimbulkan pembengkakan jaringan di sekeliling tendon bagian dalam terowongan karpal. Hal ini menyebabkan tekanan pada nervus medianus. Sedangkan faktor vaskuler berupa tekanan yang kuat dan lama serta berulang pada pergelangan tangan yang nantinya akan menyebabkan peningkatan tekanan intravaskuler, sehingga aliran darah intravaskuler akan melambat dan merusak jaringan endotel. Hal ini akan menyebabkan nyeri local pada pergelangan tangan. Beberapa faktor diketahui menjadi resiko terhadap terjadinya CTS pada pekerja seperti gerakan berulang dengan kekuatan, tekanan pada otot, getaran, suhu, postur yang tidak ergonomic dan lain-lain [7] [8].
Penyebab lain yang menyebabkan terjadinya kondisi CTS yaitu faktor mekanik, faktor non mekanik dan faktor vaskuler, ketiga faktor ini memegang faktor penting dalam terjadinya carpal tunnel syndrome. Pada umumnya carpal tunnel syndrome terjadi secara kronis dimana terjadi penebalan fleksor retinakulum yang menyebabkan tekanan terhadap nervus medianus

\subsection{Metode dan Teknik Intervensi \\ 2.2.1 Neuromuskuler Taping (NMT) a. DefinisiNeuroMuscular Tapping}

NeuroMuscular Taping (NMT) adalah aplikasi spesifik dari pita perekat elastis ke permukaan kulit dengan teknik stimulasi eksentrik menghasilkan dekompresi dan dilatasi pada daerah yang tertutupi yang digunakan untuk tujuan terapeutik. NMT bertujuan untuk mengurangi sumbatan dari cairan tubuh, meningkatkan sirkulasi pembuluh darah dan kelenjar getah, menurunkan kelebihan panas, dan memperbaiki homoestasis jaringan, mengurangi peradangan dan hipersensitivitas reseptor nyeri

\section{b. Efek Neuromuscular Tapping}

Penerapan NMT mampu merangsang mechanoceptors kulit. Reseptor ini mengaktifkan impuls saraf ketika beban mekanik (sentuhan, tekanan, getaran, peregangan dan gatal) membuat deformasi. Aktivasi oleh stimulus yang memadai menyebabkan depolarisasi lokal, yang memicu impuls saraf di sepanjang serabut aferen bepergian ke sistem saraf pusat. Efek terapeutik NMT dengan menggunakan rangsangan decompressive untuk mendapatkan efek positif dalam muskuloskeletal, pembuluh darah, limfatik dan sistem saraf, meningkatkan sirkulasi darah, dan menghilangkan rasa sakit. Aplikasi yang benar juga dapat membantu untuk memperbaiki keselarasan sendi, otot, dukungan selama gerakan, dan meningkatkan stabilitas dan postur tubuh. NMT mempunyai tujuan yaitu meringankan rasa sakit, menormalkan ketegangan otot,menghilangkan kongesti limfatik dan vena, meningkatkan vaskularisasi darah, mengoreksi keselarasan bersama dan meningkatkan postur tubuh.

\section{c. Mekanisme Neuromuscular Tapping}

Pengaplikasian Neuromuscular Taping (NMT) dengan teknik decompression akan membentuk lipatan-lipatan pada kulit. Sehingga memberikan efek yang dapat meredakan rasa nyeri, menormalkan ketegangan otot, meningkatkan sirkulasi darah dengan memperbesar ruang intestinal dalam jaringan dengan lipatan-lipatan dari efek decompression.

\subsection{Pemeriksaan dan Pengukuran}

a. Pemeriksaan Spesifik

Pemeriksaan dan tes provokasi yang dapat membantu menegakkan diagnosa Carpal Tunnel Syndrome adalah sebagai berikut: 
1) Tinel's sign

Tes ini mendukung diagnosa bila timbul parestesia atau nyeri pada daerah distribusi nervus medianus kalau dilakukan perkusi pada terowongan karpal dengan posisi tangan sedikit dorsofleksi.

2) Phalen's test

Penderita melakukan fleksi tangan secara maksimal. Bila selama satu menit parestesia bertambah hebat, maka tes ini menyokong diagnosa. Beberapa penulis berpendapat bahwa tes ini sangat sensitif untuk menegakkan diagnosa Carpal tunnel syndrome.

3) Wrist extension test

Penderita melakukan ekstensi tangan secara maksimal, sebaiknya dilakukan serentak pada kedua tangan sehingga dapat dibandingkan. Bila dalam 60 detik timbul gejala-gejala seperti Carpal tunnel syndrome, maka tes ini menyokong diagnosa Carpal tunnel syndrome.

b. Pengukuran Nyeri

Salah satu pengukuran nyeri yaitu dengan menggunakan VAS, VAS (Visual Analogue Scale) adalah suatu alat ukur yang digunakan untuk mengukur intensitas nyeri dimana nyeri diukur dengan menggunakan garis lurus dengan ukuran 10 $\mathrm{cm}$ yang menggambarkan intensitas nyeri. Di ujung sebelah kiri garis diberi tanda yang berarti "tidak nyeri" sedangkan di ujung sebelah kanan diberi tanda "nyeri yang tidak tertahankan". Pasien memberi tanda di sepanjang garis tersebut sesuai dengan intensitas nyeri yang dirasakan, nyeri diukur sebelum dan sesudah dilakukan intervensi.

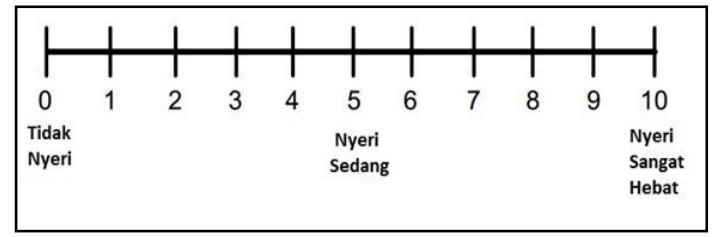

Gambar 1

AlatUkur Nyeri dengan VAS

\section{Metode Penelitian}

\subsection{Rancangan Penelitian}

Jenis penelitian yang digunakan adalah penelitian case study dengan desain penelitian pre and post test yaitu membandingkan antara tingkat nilai nyeri sebelum dan sesudah diberikan intervensi Neuromuskuler Taping pada kondisi carpal tunnel syndrome selama 3 mingggu.

\subsection{Tempat dan Waktu}

Penelitian dilakukan di Laboratorium Program Studi D-III Fisioterapi Universitas Abdurrab pada tanggal 7 Juli s/d 25 Oktober 2019.

\subsection{Teknik Pengambilan Sampel}

Dalam penelitian ini teknik pengambilan sampel yang digunakan adalah teknik cluster sampling yaitu pemilihan sampel mengacu pada kelompok dengan karakteristik tertentu yang telah ditetapkan. Melakukan random sejumlah sampel dari populasi yang ada. Sampel yang terpilih menjadi subjek penelitian diberikan penjelasan mengenai tujuan penelitian, manfaat penelitian serta diberikan penjelasan mengenai program penelitian yang akan dilakukan. Sampel yang bersedia mengikuti program penelitian diminta mengisi informed consent.

\subsection{Prosedur Intervensi}

Langkah-langkah yang diambil dalam prosedur penelitian ini dibagi menjadi tiga bagian yaitu: prosedur administrasi, prosedur pemilihan sampel dan Tahap pelaksanaan penelitian.

1) Prosedur administrasi

Prosedur administrasi dilakukan disini menyangkut: (1) Persiapan surat informed consent persetujuan sampel mengikuti program penelitian dan memberikan informasi terkait pelaksanaan program penelitian, (2) Mempersiapkan blangkoblangko dan alat pengukuran yaitu visual analogue scale (VAS) mengukur tingkat nyeri. (3) Mengisi blangko-blangko penelitian untuk diisi identitas diri dan mengumpulkan kembali.

2) Prosedur Pemilihan Sampel

Dalam penelitian ini teknik pengambilan sampel yang digunakan adalah teknik cluster sampling yaitu pemilihan sampel mengacu pada kelompok dengan karakteristik tertentu yang telah ditetapkan yaitu Kriteria Inklusi: (1) Karyawan dan Mahasiswa universitas abdurrab usia 18-30 tahun (2). Bersedia menjadi subjek penelitian dari awal hingga akhir penelitian dan menyetujui dengan menandatangani informed consent.; Kriteria Ekslusi: (1) Karyawan dan mahasiswa yang menolak berpartisipasi dalam penelitian ini (2) Karyawan dan mahasiswa yang sudah mengikuti intervensi penanganan terhadap keluhan nyeri akibat CTS namun nyeri masih dirasakan (3) Mengalami gangguan jantung (4) Sampel tidak bersedia menjadi subjek penelitian; Kriteria Drop Out: (1) Peserta yang mengkonsumsi obat-obatan yang mengandung penghilang rasa nyeri selama penelitian dilaksanakan (2) Peserta yang tidak mengikuti kegiatan secara penuh sehingga tidak dapat mencukupi frekwensi latihan selama waktu penelitian yang telah ditentukan (3) Saat penelitian, sampel mengalami penyakit yang menghambat proses intervensi

3) Tahap Pelaksanaan Penelitian

Tahap pelaksanaan penelitian menyangkut: (1) Menyiapkan form pengukuran. (2) Membuat jadwal pengambilan data. (3) Intervensi dilakukan selama 3 minggu dengan intensitas pemasangan neuromuscular taping yaitu 2 kali seminggu pada setiap sampel. (4) Setelah mendapatkan intervensi 
selanjutnya dilakukan evaluasi dengan mengukur perubahan tingkat nyeri.

\section{Hasil dan Pembahasan}

\subsection{Hasil Penelitian}

Hasil penelitian yang telah dilakukan selama 3 minggu pemberian Neuromusculer Taping terhadap 5 orang sampel dengan kondisi Carpal Tunnel Syndrom didapatkan hasil pada masing-masing sampel penelitian sebagai berikut:

a. Deskripsi Sampel

Karakteristik subjek sampel penelitian yang termasuk data jenis kelamin, usia (tahun), berat bada (kg), tingggi badan $(\mathrm{m})$ dan berat badan $(\mathrm{kg})$ dan Indeks Masa Tubuh. Keseluruhan data karakteristik sampel diuji dengan Analisa deskriptif pada SPSS yang menunjukkan normalitas data sampel, ditunjukkan pada tabel 1 berikut:

Tabel 1

Uji Normalitas Karakteristik Sampel

\begin{tabular}{lc}
\hline \multirow{2}{*}{ Karakteristik } & $\begin{array}{c}\text { Uji Normalitas } \\
\text { Shapiro Wilk Test }\end{array}$ \\
\cline { 2 - 2 } & $\mathrm{P}$ \\
\hline Jenis Kelamin & 0.006 \\
Usia & 0.046 \\
Berat Badan (kg) & 0.000 \\
Tinggi Badan (m) & 0.006 \\
Kategori IMT & 0.006 \\
VAS Sebelum & 0.314 \\
VAS Sesudah & 0.314 \\
\hline
\end{tabular}

Berdasarkan tabel diatas karakteristik sampel menunjukkan bahwa data sampel berdistribusi normal.

b. Uji Beda Nilai Nyeri Sebelum dan Sesudah intervensi dengan alat ukur VAS

Distribusi data sampel berdasarkan nilai nyeri dengan menggunakan alat ukur Visual Analogue Scale (VAS) sebelum dan setelah diberikan pemasangan Neuromusculer Taping diuji dengan Uji Non Parametric paired sampel T-Test yang ditunjukkan pada tabel 2 berikut:

Tabel 2

Uji Beda Nilai Nyeri Sebelum dan Sesudah

\begin{tabular}{|c|c|c|}
\hline \multirow{2}{*}{ Nilai VAS } & \multicolumn{2}{|c|}{ Uji Paired Sample T-Tes } \\
\hline & Mean & $\mathrm{P}$ \\
\hline Sebelum & 4.2 & 0006 \\
\hline Sesudah & 7.8 & 0.000 \\
\hline
\end{tabular}

Berdasarkan tabel diatas menunjukkan bahwa nilai signifikasi yaitu 0,006 yang menunjukkan $<0.05$ dan bermakna ada pengaruh pemberian Neruromusculer taping terhadap perubahan tingkat nyeri VAS penderita Carpal Tunnel Syndrom. c. Perubahan Nilai Nyeri diukur dengan VAS Hasil perubahan nilai nyeri pada sampel penelitian disajikan dalam grafik 1 berikut:

Grafik 1

Evaluasi Tingkat Nyeri Kelompok Sampel Sebelum dan Sesudah

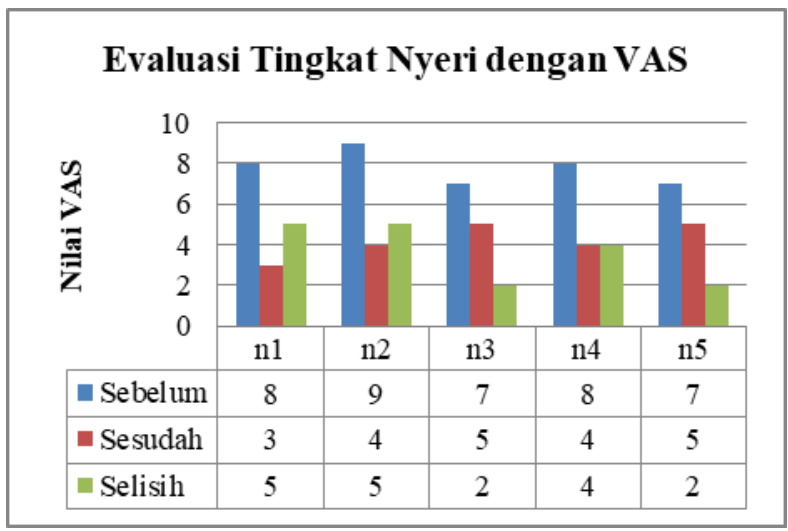

Berdasarkan grafik diatas menunjukkan bahwa seluruh sampel mengalami perubahan nilai nyeri setelah pemberian Neuromusculer Taping yang diukur dengan alat ukur VAS. Seluruh sampel penelitian mengalami penurunan nilai VAS yang bermanksa bahwa terjadi perubahan nilai nyeri menuju tidak nyeri.

\subsection{Pembahasan}

\section{Pengaruh Pemberian Neuromuscular Taping (NMT) pada Kondisi Carpal Tunnel Syndrome untuk Mengurangi Nyeri}

Carpal Tunnel Syndrome (CTS) adalah kumpulan gejala dan tanda akibat penekanan nervus medianus yang ada di pergelangan tangan yang dapat menyebabkan parastesia/ kesemutan, nyeri, mati rasa dan kelemahan pada distribusi nervus medianus pada tangan.

Beberapa faktor pekerjaan yang dapat mempengaruhi terjadinya CTS menurut Silverstein (1987), adalah gerakan pergelangan atau jari tangan yang berulang, kontraksi yang kuat pada tendon, gerakan pergelangan tangan yang menekuk ke bawah (flexi) atau menekuk ke atas (extensi), gerakan tangan saat bekerja (gerakan menjepit) dan tekanan mekanik pada saraf medianus. Sedangkan menurut penelitian yang dilakukan oleh Armstrong et al. (2008), perkembangan CTS dipengaruhi oleh empat faktor kontrol yaitu jenis kelamin, usia, index massa tubuh (IMT) dan penyakit penyerta. CTS merupakan hasil dari kombinasi kondisi kesehatan dan aktivitas fisik yang berulang yang dapat meningkatkan tekanan pada saraf medianus [9].

NeuroMuscular Taping (NMT) adalah aplikasi spesifik dari pita perekat elastis ke permukaan kulit dengan teknik stimulasi eksentrik 
menghasilkan dekompresi dan dilatasi pada daerah yang tertutupi yang digunakan untuk tujuan terapeutik. Dalam rehabilitasi, NMT diterapkan menggunakan protokol yang dirancang untuk mengurangi sumbatan dari cairan tubuh, meningkatkan sirkulasi pembuluh darah dan kelenjar getah,menurunkan kelebihan panas, dan memperbaiki homoestasis jaringan, mengurangi peradangan dan hipersensitivitas reseptor nyeri [4]. Aplikasi eksentrik dari NeuroMuscular Taping (NMT) pada kulit akan meningkatkan fungsi dari jaringan otot, tendon, pembuluh saraf, dan limfatik. NMT dengan teknik eksentrik akan mempengaruhi fleksibilitas dan memperbaiki koordinasi gerakan pada pasien dengan koordinasi otot yang menurun. Penerapan NMT mampu merangsang mechanoceptors yang ada di kulit.

\section{Kesimpulan}

Berdasarkan analisis penelitian yang telah dilakukan dan pembahasan dapat disimpulkan bahwa penerapan Neuromusculer taping pada kondisi Carpal Tunnel Syndrom dengan frekensi 2 kali dalam seminggu selama 3 minggu memberikan pengaruh terhadap perubahan nilai nyeri pada sampel penelitian.

\section{REFERENSI}

[1]. Lukman, Ns. \& Ningsih, N. (2009). Asuhan Keperawatan pada Klien dengan Ganguan Sistem Muskuloskeletal. Jakarta : Salemba Medika.

[2]. Tana, Lusianawaty. 2004. Sindrom Terowongan Karpal pada Pekerja: Pencegahan dan Pengobatannya. J Kedokter Trisakti. September-Desember 2003, Vol.22 No.3. Hal: 99 -104

[3]. American Academy of Othopaedic Surgeons. 2008. Clinical Practice Guideline on the Diagnosis of Carpal Tunnel Syndrom. Rosemont: American Academy of Orthopaedic Surgeons.

[4]. Blow, David. 2012. Neuromuscular Taping From Theory to Practice. Italy: Arti Grafiche Colombo

[5]. Bahrudin, M. 2011. Carpal Tunnel Syndrome(CTS). Jurnal Saintika Medika Universitas Muhammadiyah Malang. 7(14), hal 78-87.

[6]. Prakoso, Tegar Dwi \& Kurniawaty, Evi. 2017. Perempuan Berusia 65 tahun dengan Carpal Tunnel Syndrom. J Medula Unila. Vol 7. No. 2. April 2017. Hal: 144 - 149.

[7]. Kurniawan, Bina. Faktor risiko kejadian carpal tunnel syndrome (CTS) pada wanita pemetik melati di Desa Karangcengis, Purbalingga. J Promosi Kes Indon. 2008; 3(1):2-8.
[8]. Eka M. Diagnosis dan Terapi Syndrom terowongan karpal [internet]. Jakarta: Neurology Multiply; 2013 [diakse tanggal 21 Januari 2017]. Tersedia dari : http://neurology.multiply.com/.

[9]. Rohmah, Siti. 2016. Analisi Hubungan FaktorFaktor Indovidu dengan Carpal Tunnel Syndrome (CTS) pada Pekerja Konveksi Seminar Nasional IENACO - 2016. Hal: 73 79.

\section{Nama Penulis}

1. Ayu Permata, memperoleh Ahli Madya Fisioterapi pada tahun 2009 di Universitas Abdurrab. Kemudian tahun 2012 memperoleh gelar Sarjan Sain Terapan Fisioterapi di Poltekkes DR.Rusdi Medan dan pada tahun 2015 telah menyelesaikan Program Pasca Sarjana Fisiologi Olahraga Konsentrasi Fisioterapi di Universitas Udayana. Saat ini sebagai Dosen Tetap Prodi D-III Fisioterapi Universitas Abdurrab.

2. Ismaningsih, memperoleh Ahli Madya Fisioterapi pada tahun 2012 di Universitas Muhammadiyah Surakarta. Pada tahun 2015 telah menyelesaikan Program Pasca Sarjana Fisiologi Olahraga Konsentrasi Fisioterapi di Universitas Udayana. Saat ini sebagai Dosen Tetap Prodi D-III Fisioterapi Universitas Abdurrab. 